\title{
The Globalization of Health Data Will Revolutionize Medicine
}

\author{
Chaideftos Chaideftos \\ Technological Educational Institute of Eastern Macedonia and Thrace
}

\begin{abstract}
:
Life is a theater where each actor/actress gives a daily performance to the work that have written by a high level intelligent person or by high level intelligent people by the ancient years \& still written from the geniuses that affect the masses. To escape someone from this work he/she must be aware about the situation, he/she must be genius $\&$ he/she must wield influence to the people in order to wake up them from the technical reality that has been created \& still created by the big personalities of the planet.
\end{abstract}

Keywords: Base Editors, Bio-printed organs, Biosensors, CAR-T cells, CRISPR, EBC-46, Microchip organs, Multidimensional bioprinters, Prime Editing, Robotic organs. 


\section{International Academic Conference on Research in SOCIAL SCIENCES}

\section{Introduction}

A global center "World Health Bank" must be set up for the collection of biological material of all the patients of the world that suffering from diseases with the right hierarchy of e-data, with new safe \& secret telecommunication system, with global cloud computing, with artificial intelligence, with machine learning - deep learning, with machine vision, with automation \& with the best scientists of the world on these fields.

\section{Body of paper}

Biological material to be diffuse into microchip organs or into printed (from cells, stem cells \& etc of the patients) organs by multidimensional biological printers for personalized testing \& continuous monitoring of patient's biological (substances) reactions in vitro, to record the disease before tests \& the cure (in atomic - subatomic - etc levels) after continuous monitoring of multiple tests in multiple microchip organs for each person individually in order to understand in maximum levels everything about the confrontation of diseases.

There will be the technology to replace the real tissues - organs by microchip tissues organs but it is better to achieve the regeneration of the tissues - organs by changes to the blood that contains our DNA - RNA - etc. Scientists should focus on the manipulation of blood substances for regenerative medicine in order to do not need the people transplantations of simple or robotic tissues - organs - neurons - etc.

If DNA - RNA have A - B \& C - D letters - bases to the edges, scientists can add insert - embed - consolidate there in the same edges (with CRISPR - Cas systems, with Prime Editing or with Base Editors or with a combination of them or something more sophisticated) respectively $[\mathrm{A}$ - etc $(\mathrm{A}-\mathrm{Z})$ or $\mathrm{B}$ - etc $(\mathrm{A}-\mathrm{Z})$ \& $\mathrm{C}$ - etc $(\mathrm{A}-\mathrm{Z})$ or $\mathrm{D}$ - etc $(\mathrm{A}-\mathrm{Z})$, for example $\mathrm{A}$ $-\mathrm{B}-\mathrm{A}-\mathrm{C}-\mathrm{A}-\mathrm{D}-\mathrm{etc}$ or $\mathrm{B}-\mathrm{A}-\mathrm{B}-\mathrm{C}-\mathrm{B}-\mathrm{D}-\mathrm{etc} \& \mathrm{C}-\mathrm{D}-\mathrm{C}-\mathrm{E}-\mathrm{C}-\mathrm{F}-\mathrm{etc}$ or $\mathrm{D}$ $-\mathrm{C}-\mathrm{D}-\mathrm{X}-\mathrm{D}-\mathrm{Z}-\mathrm{etc}]$ letters - bases with the other edges of them to be new letters - bases for evolution or to add - insert - embed - consolidate a Synthetic DNA with the letters - bases of the another organism or organisms to the existing DNA - RNA \& later to evolve the polynucleotide chains (DNA Strands) that are the guards of our kind's genetic code.

Scientists can also edit - modify - evolve all the other biological material like DNA (with subcategories) - RNA (with subcategories) - genes - genomes - epigenomes chromosomes - chromatins - polynucleotide chains - CAS - cell membranes - cortices microbiome - neurons (neurotransmitters - neuropeptides - etc) - cells [evolution modification of T-cells (injection of killer \& helper CAR T- cells or injection of more sophisticated T-cells in thymus gland in order to propagate \& evolve the simple T-cells) in order to search \& destroy the cancer (injections of EBC-46 directly to the cancer - tumors in order to kill them in a record time after successful experiments with safety to the humans) \& evolution - modification of all the other type of cells] - stem cells - telomeres - proteins lipids - amino acids - acids - enzymes - microbes - mitochondria - exosomes - molecules atoms - subatomic particles \& everything other that exist with it's subcategories. 


\section{International Academic Conference on Research in SOCIAL SCIENCES}

It should become also mass bombardment every 6 months on the organisms with electrodes, bio - light - sound - wave - vibration - pulse - magnetic - electric \& etc stimulations, in order to wake up the body - tissues - organs - muscles - neurons - etc $\&$ the functions of the organisms.

Scientists must create robotic tissues - organs - neurons - etc that will charge from the wireless networks such as the RFID microchip implants \& to recharge also from the body pulses in order to replace the real ones or to find ways for the regeneration - evolution of our tissues - organs - neurons - cell membranes - cells - stem cells - telomeres - proteins - lipids - amino acids - acids - enzymes - microbes - mitochondria - exosomes - molecules - atoms subatomic particles - etc, ways for the armor \& evolution of DNA - RNA - polynucleotide chains - genes - genomes - epigenomes - chromosomes - chromatins - CAS - etc \& finally ways for the clearance - evolution of our veins throw safe personalized medicines or safe personalized vaccines for the achievement of immortality.

The creation also of nanoscale biosensors - microchips that will be implanted inside our organisms via vaccines in order to analyze - monitor in real time all the biological data material - substances of the organisms for the prevention of all the type of diseases (tumors cancer, aids \& etc) with the combination of multidimensional printed biological or microchip organs inside from biological printers for experiments in vitro - outside of the patient's body with his/her DNA - RNA - cells - stem cells - etc will lead us to the disappearance of diseases due to the early diagnosis, due to extra fast experiments \& due to personalized polypills [it will contains nanoscale microscopic sensors (creation of body - organism gps) in order to release the right substances at the right place] - vaccines that will also be printed by multidimensional bioprinters that will exist in every hospital - health center of the planet.

\section{Conclusion}

The technology that is needed for everything already exists. The matter is to share the data to a specific template on the cloud database all the hospitals, clinics, health centers, educational institutes \& laboratories in order to become the evolution of organisms - life a reality.

The chain of health science (Chaideftos Chaideftos) : Organisms - materials -> geniuses $\rightarrow$ diagnosis (microscopes, tests \& etc) -> experiments (with results - tests) -> creations -> continuously diagnosis of creations (microscopes, tests \& etc) -> experiments with the new creations (with results - tests) -> creations -> continuously diagnosis of creations (microscopes, tests \& etc) \& etc.

We are in the point that we can create a new form of life like the Creator of Universe created everything. Behind of every Creation there is a Creator. 


\section{International Academic Conference on Research in SOCIAL SCIENCES}

\section{References}

[1] Adli M. The CRISPR tool kit for genome editing and beyond. Nat Commun. 2018;9(1):1911. Published 2018 May 15. doi:10.1038/s41467-018-04252-2

[2] Anzalone, A.V., Randolph, P.B., Davis, J.R. et al. Search-and-replace genome editing without double-strand breaks or donor DNA. Nature (2019) doi:10.1038/s41586-0191711-4

[3] Benmebarek MR, Karches CH, Cadilha BL, Lesch S, Endres S, Kobold S. Killing Mechanisms of Chimeric Antigen Receptor (CAR) T Cells. Int J Mol Sci. 2019;20(6):1283. Published 2019 Mar 14. doi:10.3390/ijms20061283

[4] Boyle GM, D'Souza MMA, Pierce CJ, Adams RA, Cantor AS, Johns JP, et al. (2014) IntraLesional Injection of the Novel PKC Activator EBC-46 Rapidly Ablates Tumors in Mouse Models. PLoS ONE 9(10): e108887. https://doi.org/10.1371/journal.pone.0108887

[5] Kačarević ŽP, Rider PM, Alkildani S, et al. An Introduction to 3D Bioprinting: Possibilities, Challenges and Future Aspects. Materials (Basel). 2018;11(11):2199. Published 2018 Nov 6. doi:10.3390/ma11112199

[6] Konta AA, García-Piña M, Serrano DR. Personalised 3D Printed Medicines: Which Techniques and Polymers Are More Successful?. Bioengineering (Basel). 2017;4(4):79. Published 2017 Sep 22. doi:10.3390/bioengineering4040079

[7] M. A. Skylar-Scott, S. G. M. Uzel, L. L. Nam, J. H. Ahrens, R. L. Truby, S. Damaraju, J. A. Lewis, Biomanufacturing of organ-specific tissues with high cellular density and embedded vascular channels. Sci. Adv. 5, eaaw2459 (2019). DOI: 10.1126/sciadv.aaw2459

[8] Patel S, Nanda R, Sahoo S, Mohapatra E. Biosensors in Health Care: The Milestones Achieved in Their Development towards Lab-on-Chip-Analysis. Biochem Res Int. 2016;2016:3130469. doi:10.1155/2016/3130469

[9] Rees HA, Liu DR. Base editing: precision chemistry on the genome and transcriptome of living cells [published correction appears in Nat Rev Genet. 2018 Oct 19;:]. Nat Rev Genet. 2018;19(12):770-788. doi:10.1038/s41576-018-0059-1

[10] Shaban A. Khaled, Jonathan C. Burley, Morgan R. Alexander, Jing Yang, Clive J. Roberts, 3D printing of five-in-one dose combination polypill with defined immediate and sustained release profiles, Journal of Controlled Release, Volume 217, 2015, Pages 308314, ISSN 0168-3659, https://doi.org/10.1016/j.jconrel.2015.09.028.

[11] Sosa-Hernández JE, Villalba-Rodríguez AM, Romero-Castillo KD, et al. Organs-onaChip Module: A Review from the Development and Applications Perspective. Micromachines (Basel). 2018;9(10):536. Published 2018 Oct 22. doi:10.3390/mi9100536

[12] Tasoglu S, Gurkan UA, Wang S, Demirci U. Manipulating biological agents and cells in micro-scale volumes for applications in medicine. Chem Soc Rev. 2013;42(13):57885808. doi:10.1039/c3cs60042d 